\title{
DEVELOPMENTAL CHANGES IN NEUROPHYSIOLOGICAL TASTE RESPONSES FROM THE MEDULLA IN SHEEP
}

\author{
ROBERT M. BRADLEY and CHARLOTTE M. MISTRETTA* \\ Department of Oral Biology, School of Dentistry, and (C.M.M.) Department of Oral Biology, School of \\ Dentistry; Research Area, School of Nursing; and Center for Human Growth and Development, \\ University of Michigan, Ann Arbor, Mich. 48109 (U.S.A.)
}

(Accepted November 15th, 1979)

Key words: taste - development - fetus - tractus solitarius - medulla - sheep - neurophysiology.

\section{SUMMARY}

To determine whether functional characteristics of the taste system change during development, electrophysiological taste responses were recorded from neurons in the solitary complex (nucleus and tractus solitarius) in the medulla of fetal, newborn and adult sheep. Taste stimuli included $\mathrm{NH}_{4} \mathrm{Cl}, \mathrm{KCl}, \mathrm{NaCl}, \mathrm{LiCl}$, citric acid, and $\mathrm{HCl}$, applied to the anterior tongue. Fetal neurons at all ages (84-137 days of gestation) responded to stimulation of the tongue with $\mathrm{NH}_{4} \mathrm{Cl}$ and $\mathrm{KCl}$, but responses to $\mathrm{NaCl}$ and $\mathrm{LiCl}$ were only obtained in older fetuses (after 114 days of gestation), lambs and adults. Responses to citric acid were obtained at all ages; however, $\mathrm{HCl}$ responses were only infrequently obtained in young fetuses. Other developmental changes included a progressive decrease in latency of the responses to $\mathrm{NH}_{4} \mathrm{Cl}, \mathrm{KCl}$, citric acid and $\mathrm{HCl}$, and an increase in the duration of the neural response discharge as a function of gestational age. Since taste buds do not acquire the structural characteristics of the adult until the last third of gestation ( 100-147 days), these functional changes in taste response characteristics take place concurrently with structural development. Mammalian fetuses swallow amniotic fluid in utero, and, therefore, the fetal taste system is stimulated during structural and functional development. Thus, there is an opportunity for fetal gustatory experience to influence the developing taste system.

* To whom correspondence should be addressed at Dept. of Oral Biology, School of Dentistry, University of Michigan, Ann Arbor, Mich. 48109, U.S.A. 


\section{INTRODUCTION}

The sense of taste plays a primary role in guiding the selection and ingestion of food and, therefore, it is important to learn when gustatory function begins and whether there are changes during development. If changes do occur, knowledge of the time course is important because the sense of taste may be susceptible to modifying influences from the environment during early functional development ${ }^{7,25}$. Previously, we recorded multifiber taste responses from the chorda tympani nerve in fetal sheep over the last third of gestation, about 100-147 days ${ }^{6}$. These experiments demonstrated that the peripheral gustatory system of the fetal sheep is functional, but changes in response characteristics were not observed. However, reproducible neural responses were only obtained in fetuses $\geq 118$ days of gestation because nerves in younger animals were fragile and stable preparations were difficult to maintain.

To study neurophysiological taste responses in younger fetuses and to obtain more data from single neurons, we have recorded from the solitary complex (nucleus and tractus solitarius) in the medulla of fetal sheep aged 84-147 days of gestation, and in newborn lambs and adults 8,24 . In a recent short report ${ }^{26}$, we described changes in response characteristics of these taste units; neurons in younger fetuses respond to stimulation of the tongue with fewer salts and acids than do cells in older fetuses, lambs and adults. We now present additional data on the changing range of chemical responsiveness, as well as developmental changes in response latency and discharge duration, and coordinates of taste units at different ages.

\section{METHODS}

\section{Surgical preparation}

Electrophysiological responses were recorded in the solitary complex during chemical stimulation of the tongue in fetal, newborn and adult sheep. Adults and lambs were anesthetized with an intravenous injection of sodium pentobarbital (30 $\mathrm{mg} / \mathrm{kg}$ for adults; $10-20 \mathrm{mg} / \mathrm{kg}$ for lambs), and were tracheotomized and given supplemental $\mathrm{O}_{2}(2-2.5$ liters $/ \mathrm{min})$. The head was then flexed at a right angle to the body and secured in a stereotaxic apparatus.

Fetuses (anesthetized via the pregnant ewe) were delivered onto a heated table at the ewe's side, covered with warm mineral oil, and wrapped with a water-circulating heating pad and absorbent cotton. The umbilical circulation remained intact. Rectal temperature and heart rate were continuously monitored. The fetal head was flexed, clamped between atraumatic ear bars and supported by sponges under the neck.

\section{Neurophysiology}

In all animals, the skull and dura covering the medulla were removed, and the cerebellum was aspirated to reveal the floor of the fourth ventricle. The exposed brain was then covered with mineral oil at appox. $38.0^{\circ} \mathrm{C}$. Using the obex as a zero reference point, tungsten microelectrodes (impedance: $3-15 \mathrm{M} \Omega$ ) were positioned over the solitary complex and advanced into the brain with a micromanipulator. Coordinates 
were initially determined from microscopic examination of previously sectioned brains. Electrophysiological recordings of single or few unit neural activity were made using a pre-amplifier, oscilloscope, and audio monitor. Neural responses and voice cues were recorded on magnetic tape for later analysis.

A total of 61 single or few (2-3 neurons) unit preparations were stable enough to obtain reproducible chemosensitive responses to stimulation of the tongue with $0.5 \mathrm{M}$ $\mathrm{NH}_{4} \mathrm{Cl}$, used as the standard stimulus. Ammonium chloride was chosen as the standard since it was known to be effective in eliciting high frequency neural responses in adult sheep ${ }^{6}$. Thirty-one units ( 12 single, 19 few) were recorded from 22 fetuses aged 84-137 days of gestation (term $=147$ days); 18 units ( 7 single, 11 few) were from nine lambs aged 20-82 days after birth; and, 12 units ( 2 single, 10 few) were from 6 adults aged $2-9$ years.

\section{Stimuli}

Taste stimuli were $0.5 \mathrm{M} \mathrm{NH}_{4} \mathrm{Cl}, \mathrm{KCl}, \mathrm{NaCl}$, and $\mathrm{LiCl} ; 0.1 \mathrm{M}$ citric acid (pH $=2.2)$; and, $0.01 \mathrm{~N} \mathrm{HCl}(\mathrm{pH}=2.0)$. A concentration series of $0.05-1.0 \mathrm{M} \mathrm{NH}_{4} \mathrm{Cl}$ was used in 6 experiments. All chemicals were reagent grade, were dissolved in distilled water, and kept at room temperature during experiments. Twenty $\mathrm{ml}$ of each stimulus were applied to the anterior third of the tongue by syringes; the rest of the tongue remained in the mouth and was not exposed to stimuli. After 15-20 sec the stimulus was rinsed from the tongue with $20-40 \mathrm{ml}$ of distilled water. At least $30 \mathrm{sec}$ then elapsed before application of another stimulus. The quantities of stimuli used were sufficient to ensure that the tongue surface did not dry before the rinse was applied. Since the anterior tongue was extended from the mouth, it was not accessible to salivary flow during the experiments. Further, stimuli and rinses were frequent enough to remove any secretions that could have collected. We deliberately chose not to use a flow chamber for stimulating the tongue since this would have eliminated the electrical stimulus artifact; this artifact, which occurs when the stimulus first contacts the tongue was used to indicate stimulus onset for measures of latency.

Since $56 \%$ of fetal units had a spontaneous activity of less than $2 \mathrm{imp} . / \mathrm{sec}$, we searched for taste units by stimulating the tongue frequently with $\mathrm{NH}_{4} \mathrm{Cl}, \mathrm{KCl}$, or $\mathrm{LiCl}$, or by stroking with a glass rod. If a responsive unit was located, all 6 chemical stimuli were used. To monitor reproducibility, $0.5 \mathrm{M} \mathrm{NH}_{4} \mathrm{Cl}$ was used as every third or fourth stimulus.

\section{Data analysis}

Neural impulses were converted to standard pulses which were counted with a rate meter to generate histograms of impulse frequency before, during and after stimulation of the tongue with a chemical. The mean spontaneous activity for each unit was calculated by averaging impulse frequencies during all of the $5 \mathrm{sec}$ periods preceding lingual stimulations. The average response frequency for each chemical was calculated from neural activity during the second through seventh sec of the stimulation period. From these data, we determined whether or not a response occurred during stimulation of the tongue with each of the 6 chemicals. A response was defined as an increase 


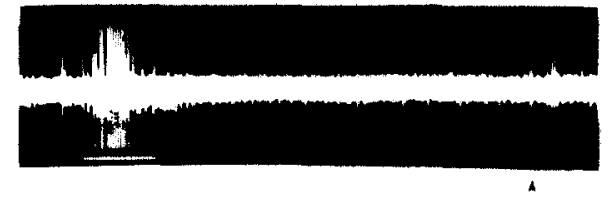

$\mathrm{NH}_{4} \mathrm{Cl}$
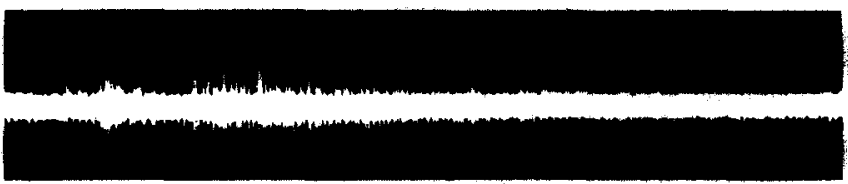

$\mathrm{KCl}$

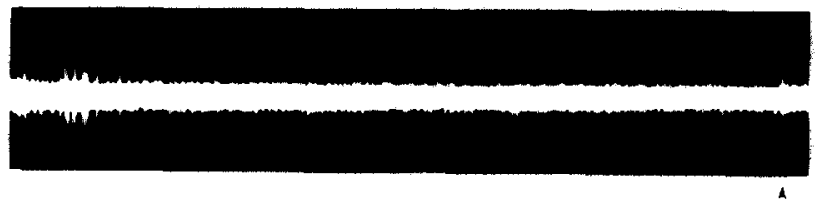

$\mathrm{NaCl}$
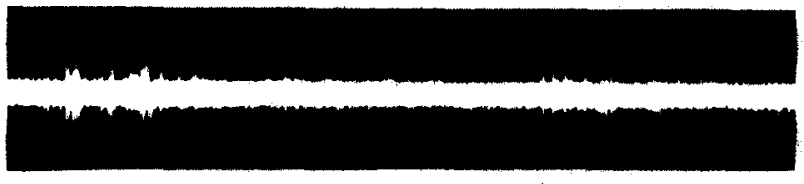

$\mathrm{LiCl}$
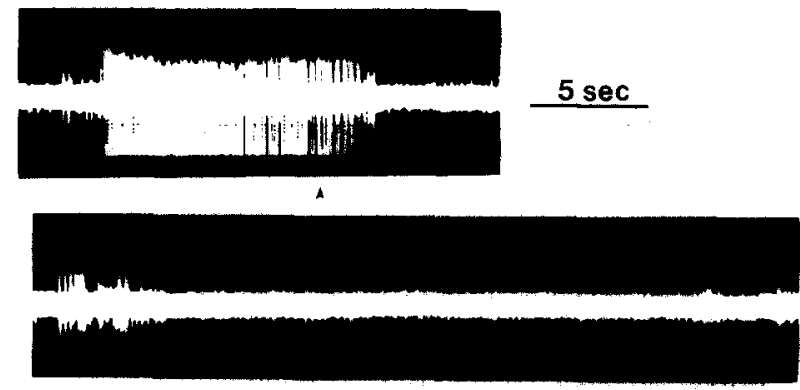

$\mathrm{HCl}$

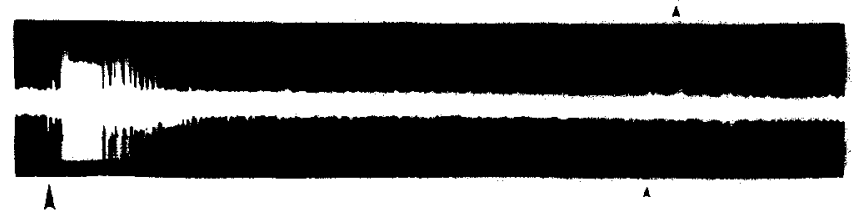

Citric acid

$\mathrm{NH}_{4} \mathrm{Cl}$

Fig. 1. Neurophysiological records from a solitary complex neuron in a fetus aged 84 days of gestation. This neuron responded to $\mathrm{NH}_{4} \mathrm{Cl}, \mathrm{KCl}$ and citric acid. The latency, or time that elapsed between the stimulus artifact and the first impulse in the response discharge, was measured for each response; for example, the latency period for the $\mathrm{KCl}$ response is indicated by a white line in the second trace. The duration of the neural response discharge was measured, also, as illustrated in the $\mathrm{NH}_{4} \mathrm{Cl}$ response by a white line under the neural impulses in the first trace. The large arrow at the bottom of the figure points to the stimulus artifact for each trace. Smaller arrows mark points at which the tongue was rinsed with waier.

in average frequency greater than the mean plus two standard deviations of the average spontaneous frequency.

Response latency (the time that elapsed between application of a chemical to the tongue and the first impulse of the neural response) and duration of the neural response discharge were measured from displays of the neural activity on a storage oscilloscope screen (Fig. 1). 


\section{Histology}

Electrolytic lesions were made after recording chemosensitive responses in 16 fetuses, 4 lambs and one adult. These animals were perfused with neutral buffered formalin at the end of the experiment, and the hindbrains were removed and placed in formalin for further fixation. Brains were embedded in paraffin, sectioned at 15-25 $\mu \mathrm{m}$, and stained with either cresyl violet or silver ${ }^{42}$. Sections were examined microscopically to establish the location of lesions. Non-lesioned brains from two additional lambs and 4 adults were also studied, to locate electrode tracks.

\section{RESULTS}

\section{Coordinates of chemosensitive units}

The anterior and lateral coordinates of 61 solitary complex units that responded to chemical stimulation of the tongue are presented as a function of age in Fig. 2. As the medulla grows, the anterior and lateral coordinates increase in a linear relation to each other, but each coordinate increases nonlinearly as a function of age. Coordinates for lamb and adult units are clustered in an area smaller than 1 sq. $\mathrm{mm}$. Fetal coordinates are widely dispersed because the range of gestational ages is large.

The electrolytic lesions in fetuses, lambs and adults were located in an area

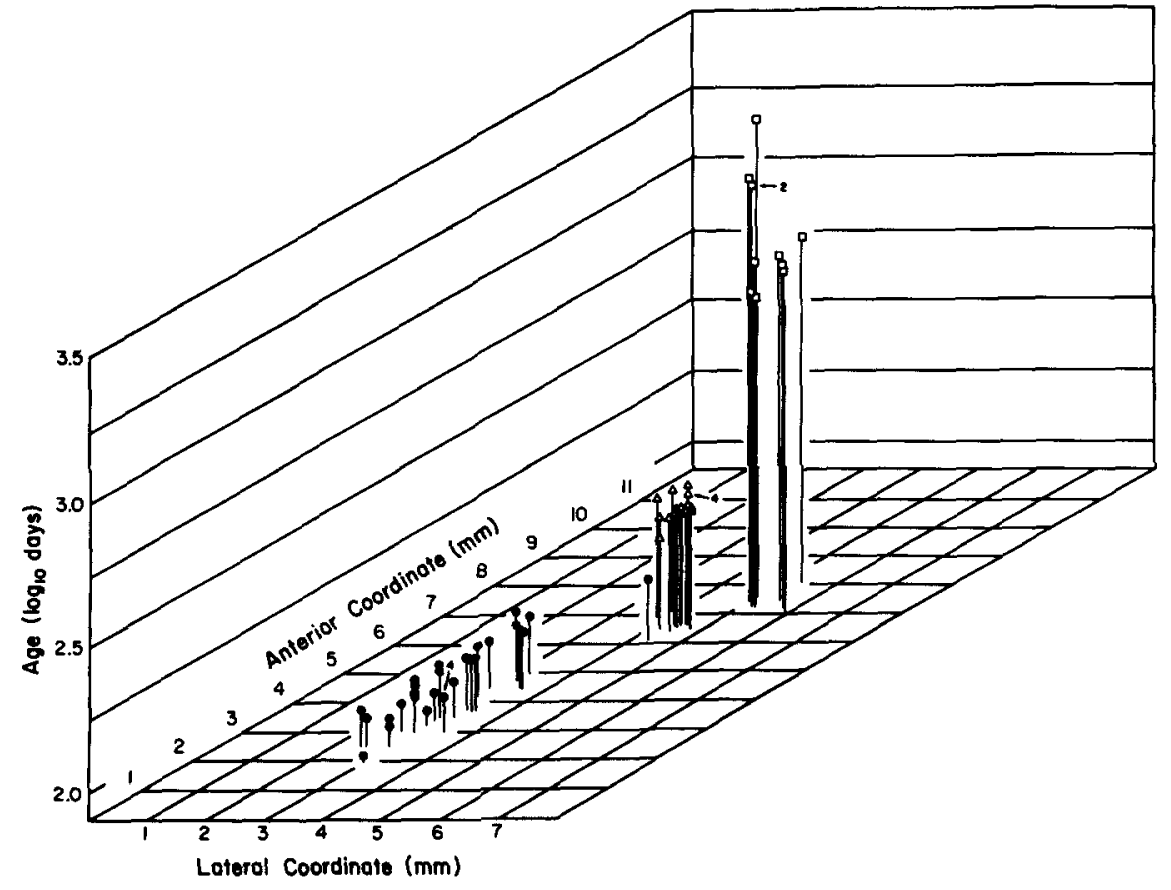

Fig. 2. Anterior and lateral coordinates for 31 fetal taste neurons $(\Theta), 18$ lamb neurons $(\triangle)$, and 12 adult neurons $(\square)$ in the solitary complex, as a function of age. The small numeral 4 pointing to one set of fetal and one set of lamb coordinates, indicates that 4 units had these same coordinates; similarly, a small numeral 2 indicates one set of coordinates for 2 adult units. Mean recording depths were $3.29 \mathrm{~mm}$ for fetal units, $4.16 \mathrm{~mm}$ for lambs, and $5.30 \mathrm{~mm}$ for adults. 

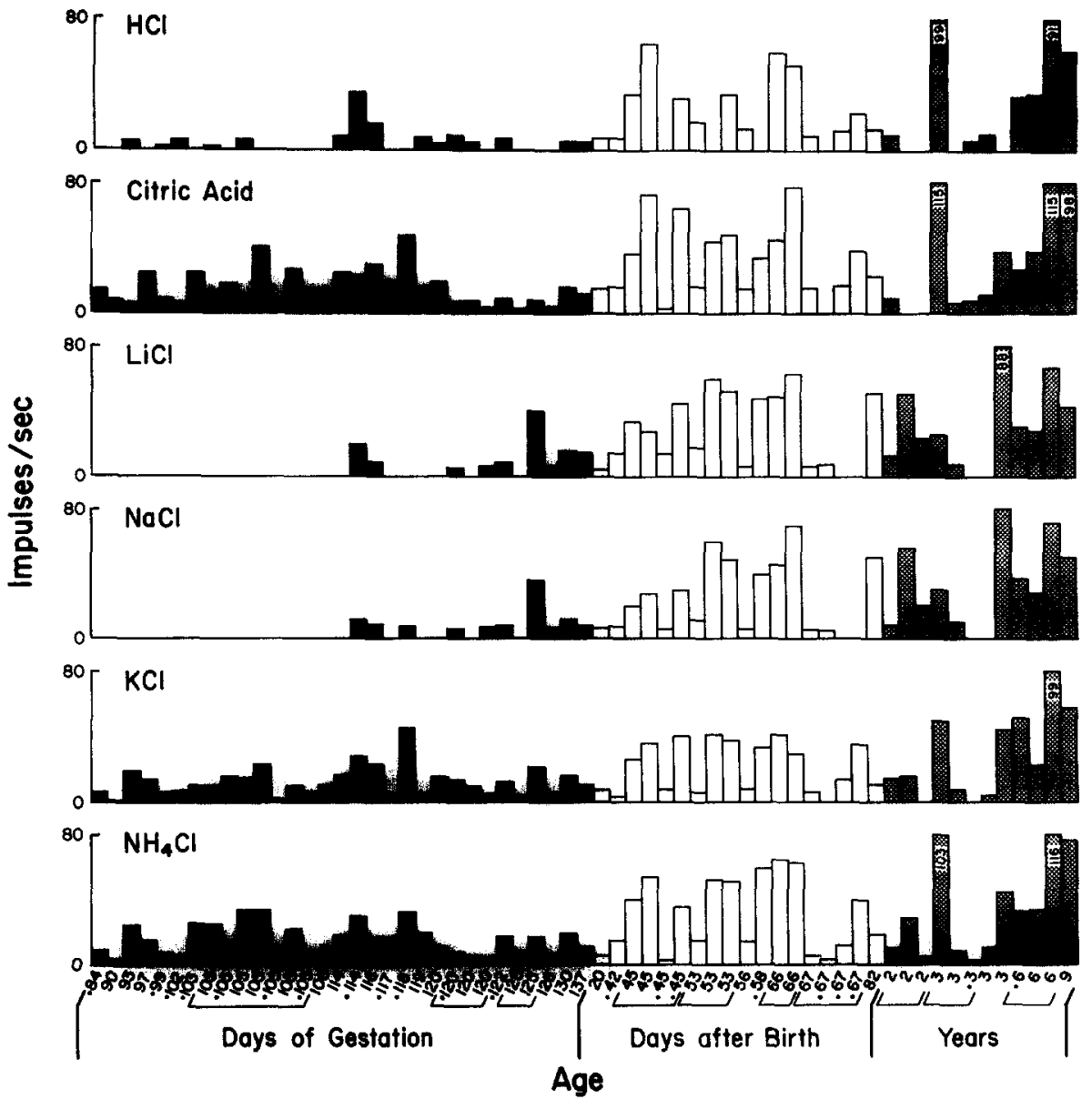

Fig. 3. Frequency histograms for responses of 61 solitary complex units to stimulation of the tongue with $\mathrm{NH}_{4} \mathrm{Cl}, \mathrm{KCl}, \mathrm{NaCl}, \mathrm{LiCl}$, citric acid, and $\mathrm{HCl}$. Ages for fetal units (black bars) are in days of gestation, tor lambs (white bars) in days after birth, and for adults (stippled bars) in years. Single units are marked by a small dot next to the age. Bracketed ages denote units recorded from one animal. The response frequencies for some adult neurons exceeded $80 \mathrm{imp}$./ $/ \mathrm{sec}$; the correct frequencies are written within the histogram bar. No responses to $\mathrm{NaCl}$ and $\mathrm{LiCl}$ were recorded in fetuses younger than 114 days of gestation.

extending from the rostral-most region of the entrance of glossopharyngeal nerve fibers into the medulla, anteriorally to the level of entering nervus intermedius fibers. From degeneration studies in cats, this region has been identified as that of the maximum projection for facial nerve fibers ${ }^{36}$.

\section{Responses to six chemical stimuli}

The responses of 61 solitary complex units to stimulation of the tongue with each of the six chemical stimuli are presented in Fig. 3. Response frequencies from both single and few unit preparations are included in the figure. We do not intend that the frequencies should be compared quantitatively. Rather, the most important point is to note where there are no responses to chemicals. 
In fetuses younger than 114 days of gestation, usually only 3 chemicals are effective stimuli $\left(\mathrm{NH}_{4} \mathrm{Cl}, \mathrm{KCl}\right.$, and citric acid). As gestational age increases, fetal units respond to more chemicals $(r=0.70 ; P<0.001)$. The mean gestational age of fetal units that respond to only three chemicals is 102 days, of those that respond to 4 chemicals, 110 days, and for 5 or 6 chemicals, 124 days $\left(F_{3,30}=9.76 ; P<0.001\right)$.

As a group, fetal units respond to fewer chemicals $(\overline{\mathrm{x}}=4.2)$ than lamb $(\overline{\mathrm{x}}=5.4)$ or adult $(\overline{\mathrm{x}}=5.0)$ units. The mean for fetal units is significantly different from that for lamb $\left(F_{2,60}=15.40 ; P<0.001\right)$ or adult units $\left(F_{2,60}=5.00 ; P<0.05\right)$, but lamb and adult means are not significantly different from each other. This indicates that the developmental change in range of responsiveness occurs prenatally, and does not continue after birth.

There are no responses to stimulation of the tongue with $\mathrm{NaCl}$ or $\mathrm{LiCl}$ in fetuses younger than 114 days of gestation (Fig. 3). Therefore younger fetuses not only respond to fewer chemicals, but also, they do not acquire the ability to respond to certain chemicals until later in gestation. These data suggest that the neural response mechanisms for $\mathrm{NH}_{4} \mathrm{Cl}$ and $\mathrm{KCl}$ are different from those for $\mathrm{NaCl}$ and $\mathrm{LiCl}$.

Responses to $\mathrm{HCl}$ were less frequent in fetuses younger than 114 days $(33 \%$ of units responded) compared to older fetuses ( $69 \%$ of units responded). Fetuses at all ages, however, responded to citric acid. This difference may relate to the fact that one stimulus is an inorganic acid which does not dissociate to the same degree as the other, organic acid, or possibly to an unequal match in stimulating effectiveness of the concentrations used.

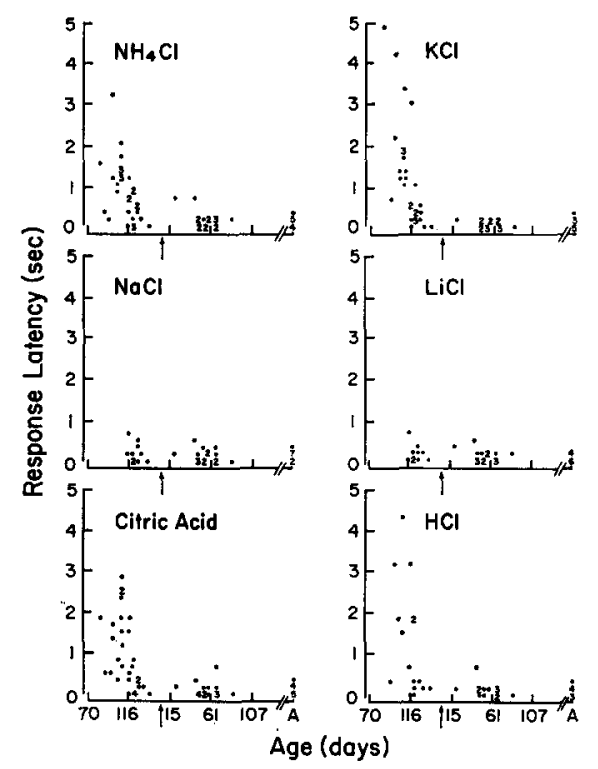

Fig. 4. Latencies for all units in response to each chemical stimulus as a function of age. An arrow under each abcissa indicates birth. Fetal ages are in days of gestation and lamb ages in days after birth. Adults are grouped together (A). Numbers are used in place of dots where two or more points overlap. 


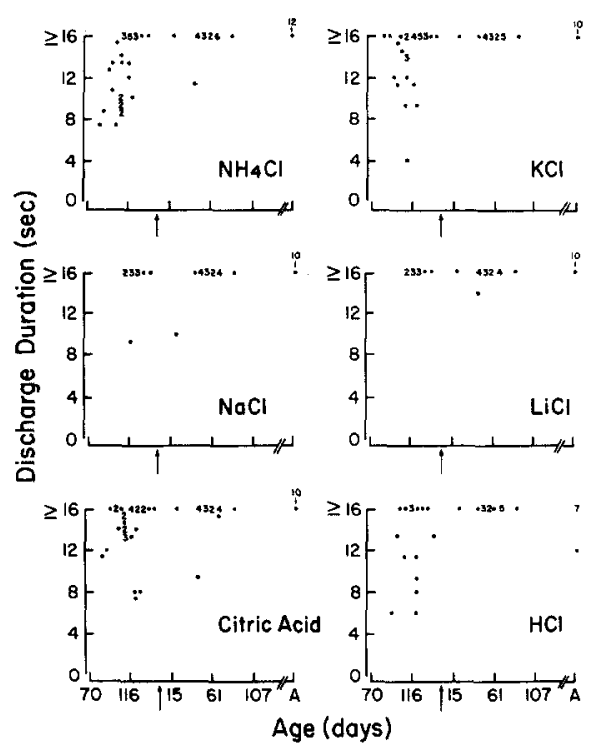

Fig. 5. Duration of the discharge in response to each chemical stimulus as a function of age. An arrow under each abcissa indicates birth. Fetal ages are in days of gestation and lamb ages in days after birth. Adults are grouped together (A). Numbers are used in place of dots where points overlap. Since all chemicals were on the tongue for at least $16 \mathrm{sec}$, but some chemicals were on for a longer time, the ordinate ends at $\geq 16 \mathrm{sec}$; a discharge of $\geq 16 \mathrm{sec}$ was sustained, therefore, until the chemical was rinsed from the tongue.

The changing range of responsiveness to the 6 chemicals could not be attributed to the different proportions of single and few unit preparations recorded at various ages. When we used the Student's $t$-test to compare numbers of chemicals that elicited responses from single unit versus few unit preparations, in neither fetuses ( $\mathrm{n}=19 \mathrm{few}$, 12 single), nor in lambs and adults ( $\mathrm{n}=21 \mathrm{few}, 9$ single), were there significant differences.

\section{Response latency}

Latencies of responses to stimulation of the tongue with $\mathrm{NH}_{4} \mathrm{Cl}, \mathrm{KCl}$, citric acid, and $\mathrm{HCl}$ progressively decreased during gestation, and adult values were only consistently reached after birth (Fig. 4). Latency functions for $\mathrm{NaCl}$ and $\mathrm{LiCl}$ are flat, since responses to these chemicals did not occur in fetuses $<114$ days of gestation (Fig. 4). Therefore when the taste system does acquire the ability to respond to $\mathrm{NaCl}$ and $\mathrm{LiCl}$, the developmental latency curve is not reproduced but response latencies are appropriate for the advanced fetal age.

\section{Duration of neural discharge}

The duration of the neural discharge during chemical stimulation of the tongue increased during development. In younger fetuses, the discharge frequency in response to $\mathrm{NH}_{4} \mathrm{Cl}, \mathrm{KCl}$, citric acid, and $\mathrm{HCl}$ often adapted to pre-stimulus, spontaneous activity levels before the chemical was rinsed from the tongue (Fig. 5). Sustained discharges were obtained in older fetuses, lambs and adults. Functions for duration of the discharge during stimulation with $\mathrm{NaCl}$ and $\mathrm{LiCl}$ are flat because younger fetuses did not respond to these chemicals. 
DISCUSSION

Neurophysiological taste responses change during fetal development in the sheep, and not until after birth are functional characteristics similar to those of the adult consistently observed. With increasing gestational age, neurons in the solitary complex respond to stimulation of the tongue with an increasing number of chemicals, and responses to $\mathrm{NaCl}$ and $\mathrm{LiCl}$ appear later in gestation than those to $\mathrm{NH}_{4} \mathrm{Cl}$ and $\mathrm{KCl}$. The duration of the neural response discharge lengthens and response latencies gradually decrease. The structural and biochemical bases of these functional changes most probably originate in different components of the gustatory system; correlates in both the peripheral and central nervous systems must be sought, and probably no single factor accounts for any of the changes.

\section{Change in range of responsiveness}

Perhaps the most intriguing developmental phenomenon is the increasing range of chemical responsiveness during gestation. Responses to taste stimuli do not develop randomly, but in a specific sequence; taste neurons respond to $\mathrm{NH}_{4} \mathrm{Cl}$ and $\mathrm{KCl}$ earlier in gestation than do $\mathrm{NaCl}$ and $\mathrm{LiCl}$. This sequence groups $\mathrm{NaCl}$ and $\mathrm{LiCl}$ as similar stimuli, contrasting with $\mathrm{NH}_{4} \mathrm{Cl}$ and $\mathrm{KCl}$. Such a partition is not new, but has appeared repeatedly in investigations of taste electrophysiology and behavior in many different species. Studies on rats ${ }^{14,17,30,33,40,44}$, hamsters ${ }^{18,31}$, rabbits $^{48}$, monkeys ${ }^{39}$, and humans ${ }^{23,45}$ have demonstrated that $\mathrm{NH}_{4} \mathrm{Cl}$ and $\mathrm{KCl}$ have bitter and sour, as well as salty, taste components, and elicit similar neural responses when compared with $\mathrm{NaCl}$ and $\mathrm{LiCl}$, which also taste alike and elicit similar responses.

Stemming from the initial work of Beidler ${ }^{2,4}$ several investigators have speculated on the mechanism of taste stimulation by salts ${ }^{5,12,27,29}$. The main factor affecting membrane discrimination among the alkali cations is thought to relate to changes in free energy when hydrated cations interact with membrane negative charges ${ }^{13}$. Binding is, therefore, influenced by the electric field strength of the negative site, which in turn can be influenced by the site's immediate molecular environment. So, as discussed by Beidler and Gross ${ }^{5}$, the same types of sites (e.g. carboxyl, phosphate, sulphate groups) may bind cations differently depending on the microenvironment of the site. Subtle structural and/or biochemical alterations in cell membranes and their environment could be involved in the gradual acquisition of responsiveness to lingual stimulation with $\mathrm{NaCl}$ and $\mathrm{LiCl}$ during fetal development. Since $0.5 \mathrm{M}$ monochloride salts are relatively strong stimuli that elicit high frequency responses in adult sheep, it is unlikely that acquisition of $\mathrm{NaCl}$ and $\mathrm{LiCl}$ responses simply relates to a change in receptor sensitivity. Responses of six solitary complex neurons to a concentration series of $\mathrm{NH}_{4} \mathrm{Cl}$, and of one neuron to a $\mathrm{LiCl}$ concentration series, indicated that $0.5 \mathrm{M}$ salts elicit maximal response frequencies, falling on the plateau of the response-concentration functions.

Although the contrast between development of $\mathrm{NaCl}-\mathrm{LiCl}$ versus $\mathrm{NH}_{4} \mathrm{Cl}-\mathrm{KCl}$ responses complements a wealth of literature on the dichotomy between these salt groups in the taste system of several species, alternative explanations for the acquisi- 
tion of responses to $\mathrm{NaCl}$ and $\mathrm{LiCl}$ should be considered. One could speculate that the $0.5 \mathrm{M}$ monochloride salts are not stimulating taste receptors in very young fetuses, but rather are diffusing through the immature tongue epithelium to stimulate nerve endings, within or near the taste bud, directly.

There are no ultrastructural data on developing sheep tongue to indicate when the keratinized layers that prevent penetration of chemicals are acquired, or when tight junctions are formed between the apices of taste bud cells. From consideration of response characteristics, however, there are no compelling reasons to assume direct stimulation of nerve endings, and indeed there are arguments to indicate that this certainly not the case. Beidler ${ }^{3}$ has discussed chemical stimulation of nerve endings in frog skin noting chemical sensitivity quickly declines on repeated stimulation. Chemicals can also directly stimulate the frog sciatic nerve ${ }^{22}$; the lowest concentrations that will stimulate are: $0.5 \mathrm{M} \mathrm{NH}_{4} \mathrm{Cl}, 0.2 \mathrm{M} \mathrm{KCl}, 0.09 \mathrm{M} \mathrm{NaCl}, 0.5 \mathrm{M} \mathrm{LiCl}$, $0.10 \mathrm{M}$ citric acid, and $0.14 \mathrm{~N} \mathrm{HCl}$. These chemicals elicit a response only after a latency of several minutes, and $\mathrm{NH}_{4} \mathrm{Cl}, \mathrm{KCl}, \mathrm{HCl}$, and citric acid rapidly destroy the preparation.

In contrast to the response characteristics of direct nerve ending stimulation, the fetal taste neurons respond reproducibly to repeated stimulation, even though the tongue may have been stimulated for hours, and the latencies are on the order of milliseconds, not minutes. Also, the taste neurons respond selectively to the $0.5 \mathrm{M}$, monovalent cations, and, $0.5 \mathrm{M}$ salts are not the lowest concentrations that will stimulate, but approach maximal effectiveness. Indeed, if we hypothesized that $0.5 \mathrm{M} \mathrm{KCl}$, for example, were diffusing through the tongue epithelium to stimulate nerve terminals or axons, then a depression of activity, rather than a neural response, would be predicted $10,20,47$.

Grobstein and Chow ${ }^{19}$ have discussed sources of sampling biases when recordings from the developing nervous system are compared to those from the adult. Among these biases is the possibility that different neuron populations are studied in immature and mature animals. For example, we may be recording from large, 'narrowly tuned' neurons in younger fetuses and ignoring smaller, 'broadly tuned' cells that are too small to be accessible; in older fetuses, both populations may have attained a critical size, so that we record from smaller, broadly tuned cells and larger, narrowly tuned cells. The consistent lack of responses to $\mathrm{NaCl}$ and $\mathrm{LiCl}$ in younger fetuses speaks against this possibility of sampling bias. Also, according to the reasoning presented, one might expect to record from more narrowly than broadly tuned cells in older animals as well as fetuses, whereas the converse is true. Comparison of chorda tympani nerve responses in young fetuses with responses of solitary complex neurons would help to resolve the question of sampling biases in central nervous system cells. We now have data that demonstrate similar changes in responsiveness to the same series of $0.5 \mathrm{M}$ salts when recordings are made from the developing sheep chorda tympani nerve ${ }^{9}$. Therefore, the increasing range of chemical responsiveness seems indeed to be related to changes in the peripheral taste system. 
Changes in response latency and discharge duration

Decreasing response latencies during development have been observed in studies of the auditory, visual, and tactile systems in a variety of species $16,28,34,35,37,41$. The long latencies that are consistently found in very young animals are generally attributed to a combination of immature receptors and synapses, and incomplete myelination of neural pathways. Some investigators, however, have commented on the relatively small fraction of the total change that is related to receptor and synaptic delay, and place more emphasis on development of afferent fiber systems, including myelination ${ }^{16}$.

From X-ray diffraction, biochemical, and histochemical studies in sheep fetu$\operatorname{ses}^{21,32,38}$, it appears that although myelin has begun to form in peripheral nerves at about 65 days of gestation, not until about 105 days is peripheral nerve myelination 'complete'. The solitary tract and brain stem undergo a period of rapid myelination between about 80 and 110 days of gestation, little or no myelin being present before this time. Brain stem myelination continues after birth, with a second, peak period of increased myelination at appox. 10 days postnatally ${ }^{32}$. Therefore, the long latencies in solitary complex responses to chemical stimulation of the tongue in fetuses from 84 to approx. 110 days of gestation coincide with periods of peripheral nerve and brain stem myelination.

Increased duration of the neural response discharge as a function of age has also been reported in studies of the developing cat auditory system ${ }^{11,37}$, and developing muscle receptors ${ }^{43}$ and cutaneous sense organs ${ }^{15}$. The change to a more sustained response discharge is accompanied in all of these systems by a gradual increase in

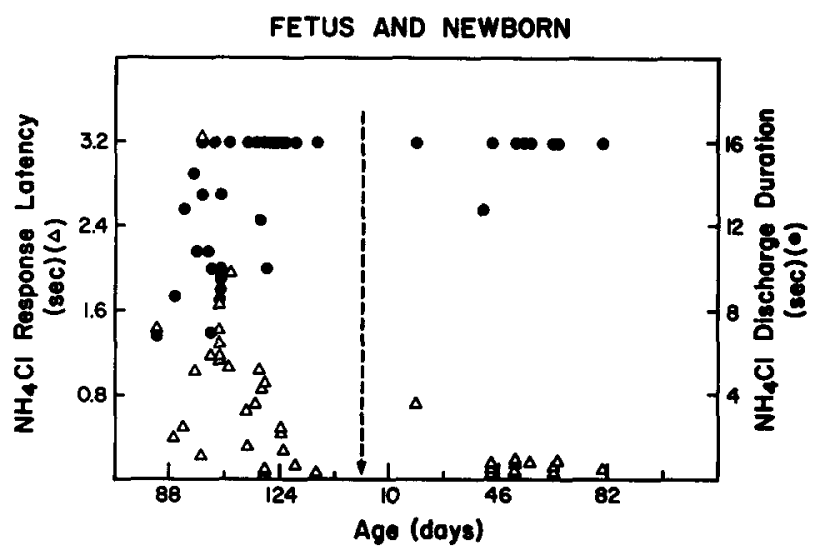

Fig. 6. Response latency $(\triangle)$ and discharge duration $(O)$ as a function of age during stimulation of the tongue with $\mathrm{NH}_{4} \mathrm{Cl}$ in fetuses and lambs. An arrow marks birth; fetal ages are in days of gestation and lamb ages in days after birth. The functions for latency and discharge duration follow a similar time course. 
average response frequency. Skoglund and Ekholm suggest that immature neurons may respond at lower frequencies and adapt more rapidly because the duration of the absolute refractory period is longer, and the ability of the fiber to produce action potentials is more rapidly diminished. They note that sustained discharges in both muscle and cutaneous receptor afferents in the cat appear when fiber conduction velocity reaches approx. $20 \mathrm{~m} / \mathrm{sec}^{15,43}$, and suggest that increased duration of the response discharge is related to increased myelination, as is response latency. Taste units in the solitary complex appear to acquire 'mature' latency and discharge duration values concomitantly (Fig. 6), providing further evidence that these two response characteristics may be related to a common developmental factor.

It is also possible that the latencies and discharge durations of the solitary complex neurons are affected by neural activity in other nongustatory oral afferents, with synaptic inputs to the rostral pole of the solitary complex via other cranial nerve nuclei. Certainly, though, the rostral pole, from which we recorded, is known to be the primary, direct projection area for taste fibers of the seventh cranial nerve ${ }^{1}$. And in adult sheep and other species ${ }^{14,46}$ the response latencies of these neurons are not unusually long, as might be predicted were other synaptic inputs to affect the responses.

\section{Early taste experience}

Although taste buds appear on the fetal sheep tongue as early as 50-55 days of gestation, the buds have not acquired adult morphological characteristics by 84 days $^{6}$. Yet, taste responses can be recorded from at least 84 days. Therefore structural maturation does not precede functional ability, but rather structure and function develop concurrently. Since sheep fetuses swallow amniotic fluid ${ }^{6}$, the taste system is stimulated while structural and functional development proceed. Increasingly, evidence indicates that sensory experience may have a role in establishing functional organization of sensory systems ${ }^{25}$. During normal development of the gustatory system, chemicals in amniotic fluid may provide a fetal taste experience that plays a role in establishing taste pathways.

\section{ACKNOWLEDGEMENTS}

This research was supported in part by National Science Foundation Grant BNS77-09920 and by a Research Career Development Award, K04 DE 00066, from the National Institute of Dental Research to C. M. M. Mr. K. Guire of the Center for Human Growth and Development, University of Michigan, provided expert assistance with data analysis.

\section{REFERENCES}

1 Beckstead, R. M. and Norgren, R., An autoradiographic examination of the central distribution of the trigeminal, facial, glossopharyngeal, and vagal nerves in the monkey, J. comp. Neurol., 184 (1979) 455-472.

2 Beidler, L. M., A theory of taste stimulation, J. gen. Physiol, 38 (1954) 133-139. 
3 Beidler, L. M., Comparison of gustatory receptors, olfactory receptors, and free nerve endings, Cold Spring Harb. Symp. quant. Biol., 30 (1965) 191-200.

4 Beidler, L. M., Anion influences on taste receptor response. In T. Hayashi (Ed.), Olfaction and Taste II, Pergamon, Oxford, 1967, pp. 509-534.

5 Beidler, L. M. and Gross, G. W., The nature of taste receptor sites. In W. D. Neff (Ed.), Contributions to Sensory Physiology, Vol. 5, Academic Press, New York, 1971, pp. 97-127.

6 Bradley, R. M. and Mistretta, C. M., The gustatory sense in foetal sheep during the last third of gestation, J. Physiol. (Lond.), 231 (1973) 271-282.

7 Bradley, R. M. and Mistretta, C. M., Fetal sensory receptors, Physiol. Rev., 55 (1975) 352-382.

8 Bradley, R. M. and Mistretta, C. M., Changes in taste responses of solitary tract neurons during development. In J. LeMagnen and P. MacLeod (Eds.), Olfaction and Taste VI, Information Retrieval, Washington, D.C., 1977, p. 276.

9 Bradley, R. M. and Mistretta, C. M., Changes in taste responses from sheep chorda tympani nerve during development, Neurosci. Abstr., 5 (1979) 125.

10 Brink, F., Bronk, D. W. and Larrabee, M. G., Chemical excitation of nerve, Ann. N. Y. Acad. Sci., 47 (1946) 457-485.

11 Carlier, E., Abonnenc, M. and Pujol, R., Maturation des réponses unitaires à la stimulation tonale dans le nerf cochléaire du chaton, J. Physiol. (Paris), 70 (1975) 129-138.

12 DeSimone, J. A. and Price, S., A model for the stimulation of taste receptor cells by salt, Biophys. $J ., 16$ (1976) 869-881.

13 Diamond, J. M. and Wright, E. M., Biological membranes: the physical basis of ion and nonelectrolyte selectivity, Ann. Rev. Physiol., 31 (1969) 581-646.

14 Doetsch, G. S. and Erickson, R. P., Synaptic processing of taste-quality information in the nucleus tractus solitarius of the rat, J. Neurophysiol., 33 (1970) 490-507.

15 Ekholm, J., Postnatal changes in cutaneous reflexes and in the discharge pattern of cutaneous and articular sense organs, Acta physiol. scand., 71, Suppl. 297 (1967) 1-130.

16 Ellingson, R. J. and Wilcott, R. C., Development of evoked responses in visual and auditory cortices of kittens, J. Neurophysiol., 23 (1960) 363-375.

17 Erickson, R. P., Sensory neural patterns and gustation. In Y. Zotterman (Ed.), Olfaction and Taste, Pergamon, Oxford, 1963, pp. 205-214.

18 Frank, M., An analysis of hamster afferent taste nerve response functions, J. gen. Physiol, 61 (1973) 588-618.

19 Grobstein, P. and Chow, K. L., Receptive field development and individual experience, Science, 190 (1975) 352-358.

20 Hodgkin, A. L. and Katz, B., The effect of sodium ions on the electrical activity of the giant axon of the squid, J. Physiol. (Lond.), 108 (1949) 37-77.

21 Höglund, G. and Ringertz, H., X-Ray diffraction studies on peripheral nerve myelin, Acta Physiol. scand., 51 (1961) 290-295.

22 Mathews, A. P., The nature of chemical and electrical stimulation. I. The physiological action of an ion depends upon its electrical state and its electrical stability, Amer. J. Physiol., 11 (1904) 455-496.

23 McBurney, D. H. and Shick, T. R., Taste and water taste of twenty-six compounds for man, Percept. Psychophys., 10 (1971) 249-252.

24 Mistretta, C. M. and Bradley, R. M., Maturation of CNS taste responses during fetal development, Ann. Rech. Vét., 8 (1977) 495-496.

25 Mistretta, C. M. and Bradley, R. M., Effects of early sensory experience on brain and behavior development. In G. Gottlieb (Ed.), Studies on the Development of Behavior and the Nervous System, Vol. IV, Early Influences, Academic Press, New York, 1978, pp. 215-247.

26 Mistretta, C. M. and Bradley, R. M., Taste responses in sheep medulla: changes during development, Science, 202 (1978) 535-537.

27 Miyake, M., Kamo, N., Kurihara, K. and Kobatake, Y., Physico-chemical studies of taste reception. IV. Response of individual phospholipid membrane to a variety of chemical stimuli, J. membrane Biol., 22 (1975) 197-209.

28 Molliver, M. E., An ontogenetic study of evoked somesthetic cortical responses in the sheep. In C. G. Bernhard and J. P. Schadé (Eds.), Developmental Neurology, Progress in Brain Research, Vol. 26, Elsevier, Amsterdam, 1967, pp. 78-91.

29 Mooser, G. and Lambuth, N., Inactivation of taste receptor cell function by two cationic protein modification reagents, $J$. Neurobiol., 8 (1977) 193-206. 
30 Morrison, G. R., Behavioral response patterns to salt stimuli in the rat, Canad. J. Psychol., 21 (1967) 141-152.

31 Nowlis, G. H. and Frank, M., Qualities in hamster taste: behavioral and neural evidence. In J. LeMagnen and P. MacLeod (Eds.), Olfaction and Taste VI, Information Retrieval, Washington, D.C., 1977, pp. 241-248.

32 Patterson, D. S. P., Sweasey, D. and Hebert, C. N., Changes occurring in the chemical composition of the central nervous system during fetal and post-natal development of the sheep, J. Neurochem., 18 (1971) 2027-2040.

33 Perrotto, R. S. and Scott, T. R., Gustatory neural coding in the pons, Brain Research, 110 (1976) 283-300.

34 Persson, H. E., Development of somatosensory cortical functions, Acta physiol. scand., Suppl. 394 (1973) 1-64.

35 Persson, H. E. and Stenberg, D., Early prenatal development of cortical surface responses to visual stimuli in sheep, Exp. Neurol., 37 (1972) 199-208.

36 Rhoton, A. L., Afferent connections of the facial nerve, J. comp. Neurol., 133 (1968) 89-100.

37 Romand, R. and Marty, R., Postnatal maturation of the cochlear nuclei in the cat: a neurophysiological study, Brain Research, 83 (1975) 225-233.

38 Romanes, G. J., The prenatal medullation of the sheep's nervous system, J. Anat. (Lond.), 81 (1947) 64-81.

39 Sato, M., Ogawa, H. and Yamashita, S., Response properties of macaque monkey chorda tympani fibers, J. gen. Physiol, 66 (1975) 781-810.

40 Scott, T. R. and Erickson, R. P., Synaptic processing of taste-quality information in thalamus of the rat, J. Neurophysiol., 34 (1971) 868-884.

41 Sedlácek, J., Foetal and neonatal development of evoked responses in guinea-pig auditory cortex, Physiol. bohemoslov, 25 (1976) 13-21.

42 Sevier, A. C. and Munger, B. L., A silver method for paraffin sections of neural tissue, J. Neuropath. exp. Neurol., 24 (1965) 130-135.

43 Skoglund, S., The activity of muscle receptors in the kitten, Acta physiol. scand., 50 (1960) 203-221 .

44 Smith, D. V. and Frank, M., Cross adaptation between salts in the chorda tympani nerve of the rat, Physiol. Behav., 8 (1972) 213-220.

45 Smith, D. V. and McBurney, D. H., Gustatory cross-adaptation: Does a single mechanism code the salty taste? J. exp. Psychol., 80 (1969) 101-105.

46 Smith, D. V., Travers, J. B. and Van Buskirk, R. L., Brainstem correlates of gustatory similarity in the hamster, Brain Res. Bull., 4 (1979) 359-372.

47 Weight, F. F. and Erulkar, S. D., Modulation of synaptic transmitter release by repetitive postsynaptic action potentials, Science, 193 (1976) 1023-1025.

48 Yamamoto, T. and Kawamura, Y., Physiological characteristics of cortical taste area. In J. LeMagnen and P. MacLeod (Eds.), Olfaction and Taste VI, Information Retrieval, Washington, D.C., 1977, pp. 257-264. 